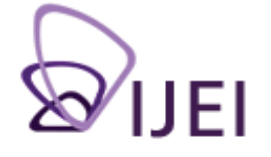

International Journal for Educational Integrity

\title{
Academic motivation and misconduct in two cultures: A comparative analysis of US and Ukrainian undergraduates
}

\author{
Jason M. Stephens \\ University of Connecticut \\ jason.stephens@uconn.edu \\ Volodymyr Romakin \\ Petro Mohyla State University \\ vromakin@gmail.com \\ Mariya Yukhymenko \\ University of Connecticut \\ mariya.yukhymenko@uconn.edu
}

Keywords: academic motivation, cheating beliefs and behaviours, cultural differences.

\begin{abstract}
The present study explored differences between United States (US) and Ukrainian undergraduates $(N=378)$ in terms of their academic motivation and its relation to their beliefs and behaviours related to academic misconduct. Specifically, this study investigated differences between US and Ukrainian students' task value, goal orientations, moral beliefs about cheating and engagement in cheating behaviour. Results revealed several significant differences between US and Ukrainian students. While similar in their level of academic task value and mastery goal orientation, Ukrainian students had reported being less performance goal oriented than their US counterparts. Ukrainian students also reported lower judgments about the wrongness of cheating and higher levels of engagement in cheating behaviour than US students. Finally, regression analyses revealed a significant culture $x$ task value interaction on both cheating beliefs and behaviours: among Ukrainian undergraduates, increases in task value both strengthen beliefs about the wrongness of cheating and reduce engagement in it. These results and their theoretical and educational significance are discussed.
\end{abstract}

\section{Introduction}

According to the Institute of International Education, the number of international students at US colleges and universities increased by $7 \%$ during the $2007 / 8$ academic year to a record high of 623,805 (Institute of International Education, 2008a). Similarly, the number of US students studying aboard increased by $8 \%$ to 241,791 during the 2006/7 academic year, continuing a decade-long trend in growth (Institute of International Education, 2008b). While these growing numbers mean increased opportunities for both international and US students, they also pose some potential challenges. The challenges are not just for students as they attempt to learn and adjust to different cultural norms, but also for instructors and administrators who must also understand and reconcile these different norms.

The International Journal for Educational Integrity is available online at:

http://www.ojs.unisa.edu.au/journals/index.php//JEI/

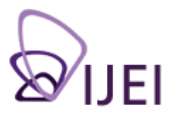


The primary purpose of the present study was to explore the potentially differing sets of norms related to academic motivation and academic misconduct amongst US and Ukrainian undergraduates. Specifically, this study was designed to address three questions:

1. Are there differences between US and Ukrainian students in terms of moral beliefs and self-reported behaviours related to academic misconduct? Specifically, do US and Ukrainian students differ in the extent to which they 1) perceive cheating as wrong, and 2) report engaging in academic cheating?

2. Are there differences between US and Ukrainian students in terms of academic motivation? Specifically, do US and Ukrainian students differ in their levels of 1) academic task value, 2) mastery goal orientation, and 3) performance goal orientation?

3. Are there differences between US and Ukrainian students in the relations between academic motivation and beliefs and behaviours related to academic misconduct? Specifically, does culture/culture moderate the relations between academic motivation (i.e., academic task value, mastery goal orientation and performance goal orientation) and beliefs and behaviours related to academic dishonesty?

\section{Literature review}

\section{Cheating across cultures}

The problem of academic misconduct has long since been characterised as an "epidemic" in the US (Haines, Diekhoff, LaBeff, \& Clark, 1986, p. 775). The largest and most comprehensive studies of academic dishonesty among American undergraduates have been conducted by Donald McCabe and his colleagues (McCabe, 1992; McCabe \& Bowers, 1994, 1996; McCabe \& Trevino, 1993, 1996, 1997; McCabe, Trevino, \& Butterfield, 2001). In his most recent report, involving nearly 50,000 undergraduates at more than 60 universities in the US, McCabe (2005) found that $70 \%$ of students engaged in some form of cheating behaviour during the past academic year. Though one might think the problem could not be any worse elsewhere in the world, empirical studies suggest otherwise.

While there have been scores of international studies of cheating, we found only two published papers comparing US students with Eastern European students. Both studies were conducted by Lupton and his colleagues. The first paper (Lupton, Chapman, \& Weiss, 2000) compared US undergraduates $(N=443)$ with Polish undergraduates, while the second paper (Lupton \& Chapman, 2002) appears to have used the same sample of US undergraduates and compared them to a sample of Russian undergraduates. In both cases, US undergraduates reported significantly lower rates of personal engagement in cheating behaviour and perceptions of peer engagement cheating behaviour than their Russian and Polish counterparts. For example, while $55 \%$ of US undergraduates admitted to having "Cheated at some point during college," $64 \%$ of Russian and $84 \%$ of Polish undergraduates admitted to doing so. More strikingly, while only $3 \%$ of US undergraduates admitted to having "Cheated in current class," $38 \%$ of Russian and $59 \%$ of Polish students admitted doing so.

Although the foregoing comparisons between US and Eastern European undergraduates are the most relevant to the present investigation, it's worth noting a few other intercultural studies. In a comparison of US and Japanese college students, Diekhoff, LeBeff, Shinohara and Yasukawa (1999) found that a significantly greater percentage of Japanese students reported cheating on a test or exam during the year they were surveyed ( $55.4 \%$ compared to $26 \%$ of US students). Finally, in a study of high school adolescents' (11th graders) thoughts and beliefs related to cheating, Evans, Craig and Mietzel (1993) found stark differences between West German students and US and Costa Rican students. Specifically, compared to US and Costa Rican students, West German students were significantly less likely to categorise a 
wide range of behaviours as cheating (such as letting other students copying your homework, "padding" the bibliography of a paper you submitted, and examining copies of older tests when the teacher has asked you not to do so).

Consistent with the existing foregoing literature, we hypothesized that compared to their Ukrainian counterparts, US undergraduates would report significantly greater beliefs about the wrongness of cheating and significantly lower levels of engagement in cheating behaviour.

\section{Academic motivation and academic misconduct}

The epidemic of cheating begs the question, why? Why are so many (most, in fact) undergraduates cheating? Over the past two decades, numerous theories of motivation have been employed in empirical studies to address this question. Among the two most prominent of these theories are expectancy-value theory (e.g., Wigfield \& Eccles, 2000) and achievement goal theory (e.g., Ames, 1992). While both theories have been used in research on cheating behaviour among undergraduates in the US, neither has been employed to explore cross-cultural differences in motivation and misconduct.

That said, there are several cross-cultural studies that used other theories or concepts to assess, or make inferences about, student motivation related to engagement in academic dishonesty. For example, Rawwas, Al-Khatib and Vitell (2004) used Foltz and Miller's (1994) six-dimension model of ethical decision-making to compare cheating behaviours between Chinese and American marketing students. One of the dimensions - "achievement/experience" - posits the existence of two basic goal orientations: achievement-orientated individuals (focused on efficiency and goal attainment) are hypothesised to cheat more than experience-oriented individuals (focused on the moment and social cooperation). However, the hypothesis was not supported for either Chinese or American students.

In US studies, students' task value beliefs (i.e., the extent to which they believe their learning experiences to be interesting, important, and/or useful) are typically negatively related to cheating (for a review, see Schraw et al., 2007). Similarly, mastery goal orientation (i.e., the extent to which one is focused on developing competence) has been negatively associated with cheating (e.g. Anderman, Griesinger, \& Westerfield, 1998; Jordan, 2001; Murdock, Hale, \& Weber, 2001; Rettinger, Jordan, \& Peschiera, 2004), while performance goal orientation (i.e., the extent to which one is focused on demonstrating competence) is often positively associated with cheating (e.g., Anderman \& Midgley, 2004; Jordan, 2001; Murdock, Miller, \& Kohlhardt, 2004).

In line with this previous research, academic task value and mastery goal orientation were hypothesized to be negative predictors of cheating behaviour while performance goal orientation was expected to be positively associated with cheating. Given the void of cross-cultural research using these theories, it is difficult to render any hypothesis about differences between US and Ukrainian students in terms of either levels of motivation (i.e., task value and goal orientation) or the relationship between motivation and misconduct. While related studies indicate that US undergraduates have become more performance oriented over time (e.g., Astin, Parrott, Korn, \& Sax, $1997)$, there's no data suggesting that they are more so compared to undergraduates in other countries or that dynamics between motivational constructs, such as goal orientation, and cheating beliefs and behaviours would be moderated by culture/ culture. Thus, the investigation of such differences in the present study was exploratory in nature, and not aimed at confirming or contradicting previous findings or building support for existing theory. 


\section{Methods}

Participants and procedures

A random sample of 1,600 undergraduate students from a large public university in the northeastern US and a mid-sized public university in Ukraine were chosen. All invitations (an initial and two reminders) were sent via email in April of 2009. These invitations described the survey as "part of an international study that is examining academic motivation and misconduct among college students in the US and Ukraine" and that their participation would "help us better understand how culture affects students' approaches to learning". The email invitations provided a web link to the online survey, and informed students that their participation would be anonymous. All invitations (and the survey) sent to US students were in English and all invitations (and the survey) sent to Ukrainian students were written in Ukrainian. No compensation was offered to either group for participation.

As detailed in Table 1 below, the final sample included a total of 378 students; remarkably, an equal number, 189 , from each culture. Similarly, participant demographics were nearly identical for each culture, though the Ukrainian sample had a moderate under-representation of sophomores and over-representation of freshmen. While seemingly low, the overall response rate of $23.6 \%$ was typical of electronic surveys (Sheehan, 2001).

Table 1:

Response rates, gender and grade level of final sample by culture and overall

\begin{tabular}{lccc}
\hline & US & Ukraine & Overall \\
\hline Response Rate & & & \\
Solicited by Email & $800(100 \%)$ & $800(100 \%)$ & $1600(100 \%)$ \\
Responded to Email & $218(27.3 \%)$ & $207(25.9 \%)$ & $425(25.9 \%)$ \\
Consented to Participate & $210(26.3 \%)$ & $200(25.0 \%)$ & $410(25.6 \%)$ \\
Completed Survey & $189(23.6 \%)$ & $189(23.6 \%)$ & $378(23.6 \%)$ \\
Gender (in Final Sample) & & & \\
Male & $81(43.5 \%)$ & $73(38.8 \%)$ & $154(41.2 \%)$ \\
Female & $105(56.5 \%)$ & $115(61.2 \%)$ & $220(58.8 \%)$ \\
Grade Level (in Final Sample) & & & \\
Freshmen & $45(23.8 \%)$ & $61(32.3 \%)$ & $106(28.0 \%)$ \\
Sophomore & $46(24.3 \%)$ & $30(15.9 \%)$ & $76(20.1 \%)$ \\
Junior & $48(25.4 \%)$ & $45(23.8 \%)$ & $93(24.6 \%)$ \\
Senior & $50(26.5 \%)$ & $53(28.0 \%)$ & $103(27.2 \%)$ \\
\hline
\end{tabular}

\section{Measures}

Participants' engagement in academic cheating behaviour was assessed with a fivepoint Likert scale (where $1=$ Never to $5=D a i l y$ ). Specifically, participants were asked to report how often, in the past academic year, they had: 1) "Copied all or part of another student's homework and submitted it as your own"; 2) "Collaborated on an assignment when the instructor asked for individual work"; 3) "Copied a sentence or more from a BOOK or ARTICLE and submitted it as your own (without citing source)"; 
4) "Copied a sentence or more from the INTERNET/WWW and submitted it as your own (without citing the source)"; 5) "Used unpermitted notes during tests or exams"; and 6) "Copied another students' work or answers during a test or exam" $(a=0.90)$.

In order to assess their beliefs about the wrongness of the foregoing six behaviours, participants were asked to use a five-point Likert scale (where $1=N o t$ at all wrong to $5=$ Very wrong) to "categorise" those "academic behaviours" $(a=0.88)$.

Participants' task value for learning was assessed with a four-item scale adapted from Wigfield and Eccles (2000). Specifically, participants used a seven-point Likert scale (ranging from $1=$ None to $7=A l l$ ) to indicate how many of their classes, in the past year, they found interesting, important, useful and enjoyable $(a=0.86)$.

Participants' mastery and performance goal orientations were assessed with items adapted from Elliot and McGregor (2001). Specifically, participants used a seven-point Likert scale (ranging from 1=Not at all true for me to 7=Very true for me) to indicate how true a series of six statements were for them: three statements pertaining to the development of competence (e.g., "It is important to me to understand the content of my courses as thoroughly as possible") and three statements pertaining to the demonstration of competence (e.g., "It is important to me to do well compared to others in my classes"). The former assessed mastery goal orientation $(a=0.84)$ and the latter performance goal orientation $(\mathrm{a}=0.89)$.

On the last page of the survey, participants were asked to indicate their gender (1=Female and 2=Male), academic level (where 1=Freshmen and 4=Senior), and what grades they typically earned (where $1=D$ s or lower and $7=$ Mostly $A s$ ).

\section{Results}

\section{Descriptive statistics and mean differences}

As described in Table 2, there were statistically significant differences between US and Ukrainian undergraduates on several of the measures employed in this study. In terms of academic motivation, US students reported being more performance goal orientated than their counterparts $(F(1,376)=63.3, p<0.001)$. In terms of academic misconduct, US students reported stronger beliefs about the wrongness of cheating $(F(1,377)=156.1$, $p<0.001)$ and less frequent cheating behaviour $(F(1,377)=144.7, p<0.001)$ than Ukrainian students. As indicated by the Cohen's $d$ values, all three effects were large.

Table 2:

Academic motivation, beliefs and behaviours related to academic misconduct: subscale summary statistics by culture

\begin{tabular}{|c|c|c|c|c|c|c|c|}
\hline & \multicolumn{2}{|c|}{ US } & \multicolumn{2}{|c|}{ Ukraine } & \multirow[b]{2}{*}{$\begin{array}{c}\text { Mean } \\
\text { Diff }\end{array}$} & \multirow[b]{2}{*}{$F$-value } & \multirow[b]{2}{*}{$\begin{array}{l}\text { Cohen' } \\
\text { s } d\end{array}$} \\
\hline & Mean & SD & Mean & SD & & & \\
\hline Academic Task Value & 4.34 & 1.17 & 4.18 & 1.13 & 0.16 & 1.84 & 0.14 \\
\hline Mastery Goal Orientation & 5.62 & 1.21 & 5.45 & 1.49 & 0.17 & 1.47 & 0.13 \\
\hline Performance Goal Orientation & 4.95 & 1.59 & 3.65 & 1.59 & 1.30 & $63.33^{* * *}$ & 0.82 \\
\hline Beliefs: Wrongness of Cheating & 4.06 & 0.69 & 2.99 & 0.95 & 1.07 & $156.1^{* * *}$ & 1.29 \\
\hline $\begin{array}{l}\text { Behaviours: Self-Reported } \\
\text { Cheating }\end{array}$ & 1.30 & 0.34 & 2.38 & 0.93 & -1.08 & $144.7^{* \star *}$ & -1.54 \\
\hline
\end{tabular}

Note. Cohen's $d=\mathrm{M} 2-\mathrm{M} 1 / \sqrt{ }\left[\left(\sigma 1^{2}+\sigma 2^{2}\right) / 2\right]$.; $d$ values between 0.2 and 0.5 constitute a small effect, 0.5 to 0.8 a medium effect, and 0.8 or greater a large effect.

*** $p \leq 0.001$ 
Mean values are derivative and while very useful in statistical analyses, they do not always convey the scope or magnitude of given phenomena. Thus, in order to more clearly describe and compare beliefs and behaviours related to cheating in the US and Ukraine, Table 3 presents percentage values of these two phenomena. As depicted below, there are large and consistent differences (across all six behaviours and overall) between US and Ukrainian undergraduates in the percentages of students that 1) believe the behaviours to be "mostly" or "very wrong" and 2) report engaging in those behaviours at least once during the 2008-2009 academic year). In short, compared to the Ukrainian counterparts, US undergraduates were significantly more likely to report believing that the six behaviours surveyed were wrong, and significantly less likely to report engagement in them.

Table 3:

Self-reported beliefs and behaviours related to six "academic behaviours": percentages by culture and chi-square values of differences.

\begin{tabular}{|c|c|c|c|c|c|c|}
\hline & \multicolumn{2}{|c|}{$\begin{array}{c}\text { Belief: } \\
\text { "Mostly" or } \\
\text { "Very Wrong" }\end{array}$} & \multirow{2}{*}{$\begin{array}{c}c^{2} \\
(1,376) \\
\end{array}$} & \multicolumn{2}{|c|}{$\begin{array}{c}\text { Behaviour: } \\
\text { Did At Least Once }\end{array}$} & \multirow{2}{*}{$\begin{array}{c}c^{2} \\
(1,376) \\
\end{array}$} \\
\hline & US & Ukraine & & US & Ukraine & \\
\hline \multicolumn{7}{|l|}{ Homework Cheating } \\
\hline $\begin{array}{l}\text { Copied from } \\
\text { Another Student }\end{array}$ & $62.8 \%$ & $46.6 \%$ & $9.9^{* *}$ & $30.7 \%$ & $72.0 \%$ & $64.4^{\star * *}$ \\
\hline $\begin{array}{l}\text { Unpermitted } \\
\text { Collaboration }\end{array}$ & $32.1 \%$ & $20.1 \%$ & $7.0^{* *}$ & $50.3 \%$ & $83.0 \%$ & $45.3^{* * *}$ \\
\hline \multicolumn{7}{|l|}{$\underline{\text { Plagiarism }}$} \\
\hline $\begin{array}{l}\text { Conventional: From } \\
\text { a printed book or } \\
\text { journal }\end{array}$ & $83.1 \%$ & $31.2 \%$ & $102.9^{\star * \star}$ & $8.0 \%$ & $57.4 \%$ & $104.5^{\star * *}$ \\
\hline $\begin{array}{l}\text { Digital: From the } \\
\text { Internet/WWW }\end{array}$ & $81.4 \%$ & $26.5 \%$ & $114.4^{\star * *}$ & $16.5 \%$ & $77.7 \%$ & $141.2^{\star \star *}$ \\
\hline \multicolumn{7}{|l|}{ Test Cheating } \\
\hline $\begin{array}{l}\text { Copied from } \\
\text { Another Student }\end{array}$ & $92.6 \%$ & $48.8 \%$ & $85.5^{\star * *}$ & $22.3 \%$ & $64.7 \%$ & $68.5^{\star * *}$ \\
\hline $\begin{array}{l}\text { Used Unpermitted } \\
\text { Notes }\end{array}$ & $91.0 \%$ & $38.6 \%$ & $113.1^{* * *}$ & $11.1 \%$ & $81.9 \%$ & $190.0^{* \star *}$ \\
\hline OVERALL & $98.4 \%$ & $67.7 \%$ & $62.3^{* * *}$ & $65.6 \%$ & $97.4 \%$ & $63.1^{* * *}$ \\
\hline
\end{tabular}

\section{Bivariate correlations}

As detailed in Table 4, the pattern of bivariate relations among the variables in this study were highly similar across the two cultures. The relations between students' beliefs and behaviours related to cheating were negative for US and Ukraine undergraduates ( $r=-0.48$ and -0.63 , respectively): as beliefs about the wrongness of cheating increased, reports of engagement in cheating behaviour decreased. Similarly, there were significant correlations between mastery goal orientation and cheating beliefs and behaviours among students from both countries: as students' emphasis on learning and developing competence increased, their judgments about 
the wrongness of cheating increased ( $r=0.33$ and 0.31 , respectively) and their selfreported engagement in cheating decreased ( $r=-0.24$ and -0.36 , respectively).

There were, however, two notable intercultural differences in the pattern of relations among variables in this study. The negative correlation between academic task value and cheating behaviour was statistically significant among Ukrainian students ( $r=-$ 0.29 ) but not among US students $(r=-0.12)$. Similarly, the positive correlation between gender (where 1=male) and cheating behaviour was statistically significant among Ukrainian students $(r=0.19)$ but not among US students $(r=0.14)$. Finally, the positive correlation between typical grades and cheating beliefs was statistically significant among Ukrainian students $(r=0.22)$ but not among US students $(r=0.08)$.

Table 4:

Correlations among all variables by culture

\begin{tabular}{|c|c|c|c|c|c|c|c|c|}
\hline & \multicolumn{8}{|c|}{ Ukraine } \\
\hline & 1 & 2 & 3 & 4 & 5 & 6 & 7 & 8 \\
\hline $\begin{array}{l}\text { 1. Behaviours: Self-Reported } \\
\text { Cheating }\end{array}$ & - & -0.63 & 0.19 & 0.04 & -0.12 & -0.29 & -0.36 & -0.07 \\
\hline 2. Beliefs: Wrongness of Cheating & -0.48 & - & -0.19 & 0.00 & 0.22 & 0.31 & 0.31 & 0.10 \\
\hline 3. Gender $(0=$ female; $1=$ male $)$ & 0.14 & -0.16 & - & 0.49 & -0.17 & -0.18 & -0.14 & -0.11 \\
\hline 4. Grade Level & -0.06 & 0.00 & -0.20 & - & 0.15 & -0.18 & -0.09 & -0.09 \\
\hline 5. Typical grades & -0.11 & 0.08 & -0.03 & 0.16 & - & 0.17 & 0.33 & 0.34 \\
\hline 6. Academic Task Value & 0.12 & 0.17 & -0.16 & 0.14 & 0.14 & - & 0.40 & 0.25 \\
\hline 7. Mastery Goal Orientation & -0.24 & 0.33 & -0.15 & -0.03 & 0.31 & 0.46 & - & 0.32 \\
\hline 8. Performance Goal Orientation & 0.04 & 0.08 & 0.03 & 0.02 & 0.43 & 0.06 & 0.27 & - \\
\hline
\end{tabular}

Note. All bold-faced correlation coefficients are statistically significant, $p \leq 0.05$ for $r$ 's ranger from 0.15 to $0.20, p \leq 0.01$ for all $r$ 's greater than 0.20 .

\section{Regression analyses}

To explore further relationships between academic motivation and academic misconduct among US and Ukrainian students, two multiple regressions were performed: the first using beliefs about the wrongness of cheating and the second using self-reported engagement in cheating behaviour as the dependent variables. In both regressions, culture, gender, grade level, and typical grades were entered as control variables and then academic task value, mastery goal orientations and performance goal orientations as independent variables (IVs). Given the mean level differences between the countries on several variables, interaction terms were created for all IVs (by culture) using procedures described by Aiken and West (1991).

As indicated in Table 5, the seven predictors accounted for $37 \%$ of the variance in students' beliefs that cheating is wrong, $F(8,363)=28.56, p<0.001)$ and $46 \%$ of the variance in students' engagement in cheating behaviours, $F(8,363)=39.92, p<0.001$. The final model of both equations included culture, gender, mastery goal orientation, and a culture $x$ task value interaction as significant predictors. Specifically, being Ukrainian and male were negative predictors of cheating beliefs $(B=-0.53$ and -0.09 , 
respectively) and positive predictors of cheating behaviours ( $B=0.62$ and 0.09 , respectively); conversely, mastery goal orientation was a positive predictor of students' beliefs about the wrongness of cheating $(B=0.19)$ and a negative predictor of their engagement in cheating behaviour $(B=-0.21)$. Finally, the interaction between culture and task value was also a significant predictor in both equations. These moderation effects are described in Table 5.

Table 5:

Final model statistics for all independent variables on beliefs about the wrongness of cheating and self-reported engagement in cheating behaviour

\begin{tabular}{|c|c|c|c|c|c|c|}
\hline & \multicolumn{3}{|c|}{$\begin{array}{l}\text { Beliefs: } \\
\text { Wrongness of Cheating }\end{array}$} & \multicolumn{3}{|c|}{$\begin{array}{c}\text { Behaviours: } \\
\text { Self-Reported Cheating }\end{array}$} \\
\hline & $\mathrm{B}$ & SE & Beta & $\mathrm{B}$ & SE & Beta \\
\hline Culture (0=US, $1=$ Ukraine) & -0.52 & 0.044 & $-0.53^{* * *}$ & 1.10 & 0.074 & $0.62^{* * *}$ \\
\hline Gender $(0=$ Female, $1=$ Male $)$ & -0.09 & 0.042 & $-0.09^{*}$ & 0.08 & 0.035 & $0.09^{*}$ \\
\hline Grade Level & 0.01 & 0.036 & 0.01 & -0.02 & 0.035 & -0.02 \\
\hline Typical Grades & 0.05 & 0.041 & 0.06 & -0.01 & 0.038 & -0.01 \\
\hline Academic Task Value & 0.09 & 0.039 & $0.11^{*}$ & 0.05 & 0.050 & 0.06 \\
\hline Mastery Goal Orientation & 0.14 & 0.035 & $0.19^{* * *}$ & -0.19 & 0.040 & $-0.21^{* * *}$ \\
\hline Performance Goal Orientation & -0.02 & 0.028 & -0.03 & 0.06 & 0.040 & 0.07 \\
\hline $\begin{array}{l}\text { Culture x Task Value Interac- } \\
\text { tion }\end{array}$ & 0.08 & 0.036 & $0.09^{*}$ & -0.24 & 0.069 & $-0.19^{\star * *}$ \\
\hline Total adjusted $r$-squared & & & 0.37 & & & 0.46 \\
\hline$F$-value for model & & & $28.56^{* * *}$ & & & $39.92^{* \star \star}$ \\
\hline dfs for model & & & 8,363 & & & 8,363 \\
\hline
\end{tabular}

Note. ${ }^{*} p<0.05^{* *} p<0.01{ }^{* * *} p<0.001$

As depicted in Figure 1, the relation between task value and beliefs about the wrongness of cheating was moderated by culture. That is, the extent to which students perceived their academic studies to be interesting, important and/or useful functioned differentially in these two cultures. Among Ukrainian undergraduates, increases in task value were associated with strengthened beliefs about the wrongness of cheating (see upward slope of the dashed line, representing Ukrainian students). Among US undergraduates, task value was not associated with beliefs about the wrongness of cheating (see the relatively flat slope of the solid line, representing US students). 


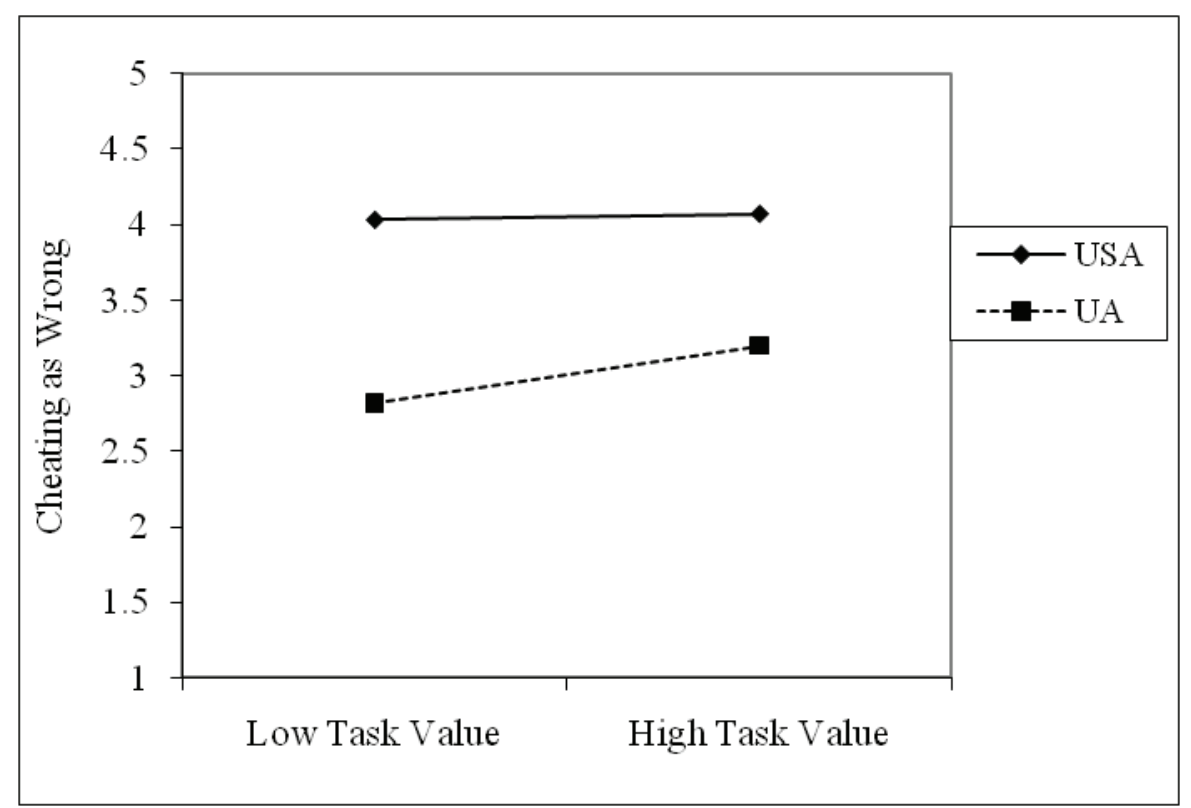

Figure 1. Culture by task value interaction on cheating beliefs

Similarly, as depicted in Figure 2, the relation between task value and cheating behaviour was also moderated by culture. Among Ukrainian undergraduates, increases in task value were associated with decreases in cheating behaviour (see downward slope of the dashed line, representing Ukrainian students). Among US undergraduates, task value was not associated with engagement in cheating behaviour (see the relatively flat slope of the solid line, representing US students).

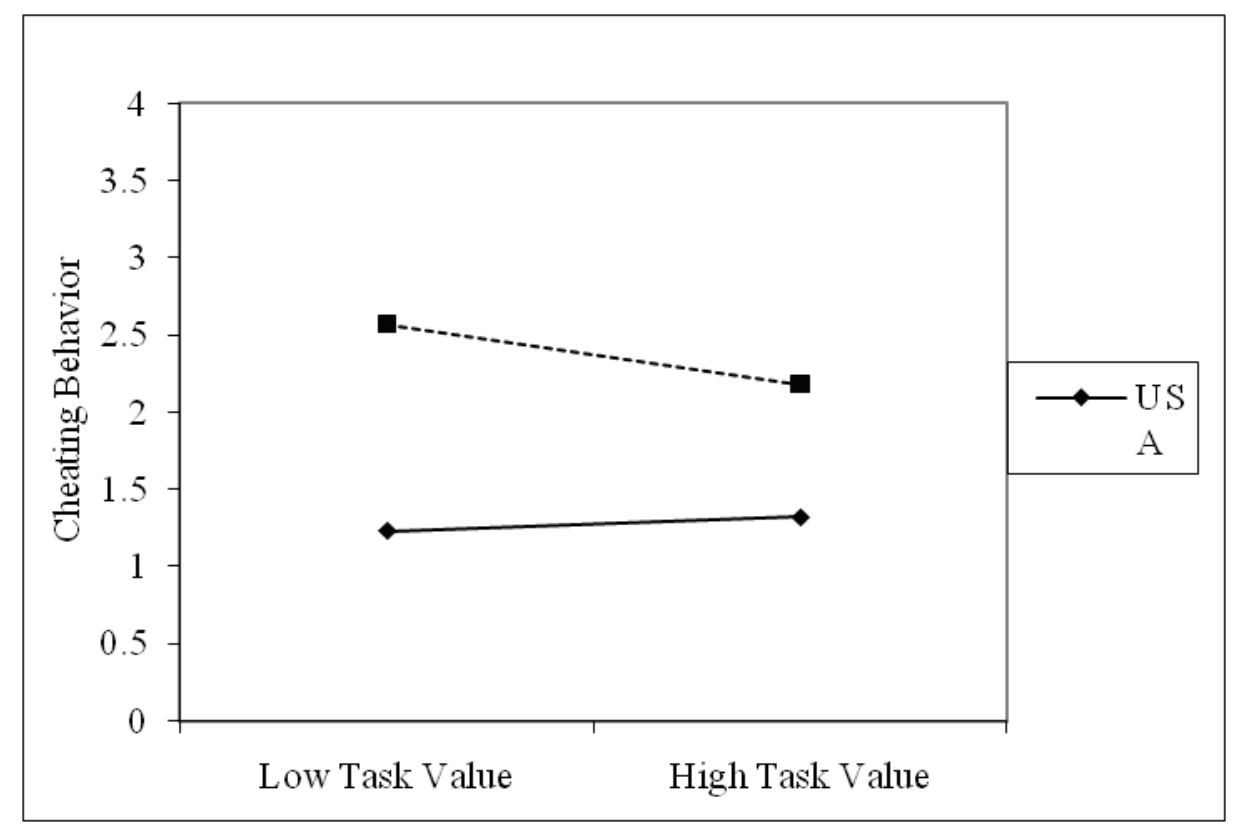

Figure 2. Culture by task value interaction on cheating behaviour 


\section{Discussion}

\section{Summary of findings}

Findings from the present study highlight some important differences in academic motivation and misconduct among US and Ukrainian students. First, and most notably, are the large difference in beliefs and behaviours related to cheating. Ukrainian undergraduates judged all six of the cheating behaviours as less wrong than US undergraduates, and the former reported engaging in all six of those behaviours more frequently than the latter. These findings supported our hypothesis and were consistent with earlier research comparing students from the US and Eastern European countries (e.g., Lupton \& Chapman, 2002; Lupton et al., 2000). Like others (e.g., Magnus, Polterovich, Danilov, \& Savvateev, 2002), we understand the stark differences in beliefs and behaviours to be a function, at least in part, of the widespread "culture of corruption" in Ukraine (Neutze \& Karatnycky, 2007). According to the most recent rankings of Transparency International's (2009) Corruption Perception Index, Ukraine ranked 146th out of 180 nations (along with seven other nations, from neighboring Russia to Sierra Leone and Ecuador) and the US ranked 19th (between the United Kingdom and Barbados). In other words, despite the deluge of corporate, economic and political scandals in the US over the past decade, its culture of corruption is still comparatively minor compared to the Ukraine's. It is very likely that these macro-level societal differences explain some the individual-level differences in students' beliefs and behaviours related to academic misconduct.

Second, while US and Ukrainian students reported equivalent levels of academic task value and mastery goal orientation, the former reported significantly higher levels of performance goal orientation. In other words, US undergraduates seem to be more concerned with demonstrating competence (by outperforming others) than their Ukrainian counterparts. The large difference observed in the present study is perhaps not so surprising when one considers some of the broader trends in US education, such as college being seen more as a means to financial success than a journey of insight and understanding (Astin et al., 1997) or the current era of highstakes testing ushered in by the No Child Left Behind Act of 2001.

Finally, the present study was designed to explore the relations between academic motivation and academic misconduct among US and Ukrainian undergraduates. Our analyses yielded two important findings. The first was a main effect for mastery goal orientation. Specifically, the adoption of mastery goals served as a "protective factor" for students from both countries in terms of strengthening judgments against cheating and reducing engagement in it. Second, a moderation effect for culture in the relations between academic task value and cheating beliefs and behaviours. Specifically, results from this study suggest that academic task value (i.e., the extent to which students see their studies as interesting, important and/or useful) functions differentially in these two countries: among Ukrainian undergraduates, increases in task value both strengthen beliefs about the wrongness of cheating and reduce engagement in it; whereas among US undergraduates, level of task value does not significantly affect beliefs or behaviours related to cheating.

\section{Educational implications}

The present study provides some insights for educators and administrators who are interested in better understanding and ultimately ameliorating the problem of academic dishonesty. First and foremost, results from this study suggest large cultural differences in beliefs and behaviours related to cheating. While universities in both countries need to create and implement efforts to help students see and judge cheating as wrong (i.e., as a violation of the core academic values of trust, honesty, fairness and responsibility), the need seems especially great in Ukraine, where a culture of corruption pervades. Helping students to recognise how issues of fairness, 
respect and honesty are at stake in behaviours such as plagiarism and test cheating is a critical step on the path to understanding and judging dishonesty as unfair and unjustifiable. Recent experimental research (Dee \& Jacob, 2010) provides an example of how relatively modest curricular interventions (in this case, an online tutorial about plagiarism) can have large effects on student beliefs and behaviours related to academic dishonesty.

Second, the findings of this study are consistent with previous studies that have shown personal mastery goals to be negatively associated with cheating (Anderman et al., 1998; Jordan, 2001; Murdock et al., 2001; Rettinger et al., 2004). These results are congruent with common sense: students who seek to master course material would be less likely to cheat as cheating would undermine the desired goal of acquiring new knowledge and/or skills. Thus, instructors in both countries should help orient students toward the adoption of mastery goals by creating a learning environment that 1) emphasises the importance of individual learning, growth and understanding and, 2) de-emphasises social comparisons among students and test scores as the most important metric of "success".

Finally, findings from the present study suggested that academic task value was a significant predictor of cheating beliefs and behaviours for Ukrainian undergraduates. As Ukrainian students' beliefs about the importance, usefulness and interestingness of their course increased, their beliefs about the wrongness of cheating also increased and their reported engagement in cheating behaviour decreased. Accordingly, though good practice for all instructors, it seems especially important that Ukrainian instructors take the time to stimulate students' interests in learning and connect the content to be learned to the lives of their students; explicating, for example, how what students are learning will be important or useful to them (presently and/or in the future). Stimulating such interest and value judgments isn't always easy, but achievable in most courses with only minor modifications to the organisation and presentation of the curriculum.

\section{Limitations and future directions}

The greatest concern or limitation of any study that asks individuals to report their engagement in deviant or socially sanctioned behaviour concerns the veracity of those reports. This concern is exacerbated when this reporting takes place online, where fear of detection may be greater, and it likely accounts for both the relatively low response $(23.6 \%)$ as well as the lower incidence of self-reported cheating behaviour found in this study among US students compared to previous studies (see also McCabe, 2005).

The low response rate of this study may also be a product of a broader trend. According to Sheehan (2001), response rates of electronic surveys have steadily dropped over the period from 1986 through 2000 (61.5\% vs. 24\%, respectively). Sheehan suggests that the novelty of online surveys has worn off and that researchers use incentives and offer multiple modes of participation (e.g., mailing paper surveys with the URL of a website for those who prefer to complete the survey online) in order to increase response rates. The proliferation of online surveying (not to mention spam and filtering software to detect and redirect unsolicited, mass email) since 2000 has only increased the challenge of soliciting participation. The present study did not use incentives or offer students multiple modes of participating. Future researchers should consider doing so.

In addition to low response rates and self-selection bias of unsolicited emails to recruit participants, online surveys raise privacy concerns and many students may misrepresent their beliefs and behaviours related to cheating. Perhaps some of the large differences observed in the present study concerning these beliefs and behaviours might be explained by cultural differences in online disinhibition (e.g., 
Suler, 2004). Ukrainian students, that is, might feel more "free" and less concerned with Internet surveillance and detection than US students, who might then underreport their engagement in cheating behaviour. Remarkably, despite the recent growth of Internet surveys, there is no research exploring the effects of the mode of survey administration on student responding. We hope someone will conduct such experimental work in the near future.

The limited range of behaviours is perhaps another limitation of the present study. We only asked students about six behaviours. There are, of course, many more forms of cheating, particularly digital cheating. Future research should broaden the range of behaviours investigated, and thus our insight and understanding of academic dishonesty across cultures. Finally, although research has consistently shown that Eastern European students cheat more frequently than US students, it's not clear if the former do so while studying abroad in the US (or, conversely, if US students studying abroad in Eastern European countries cheat more than they do at their US college). Future research should explore changes in beliefs and behaviours related to academic dishonesty among international students.

Finally, it's important to note that the current study does not shed any light on the academic motivation and integrity of international exchange students (such as the third author, a Ukrainian studying in the US). Nor could we find any empirical research on cheating beliefs and behaviours of international students while studying in the US Some scholars (e.g., Magnus et al., 2002) have suggested that international students probably do not cheat (as often as they might in their home culture) while studying in the US, where they perceive the educational system to be more student-centered and less tolerant of cheating. This seems an interesting and important area of research inquiry, and one we hope other researchers might pursue.

\section{Conclusion}

The past decade has seen significant growth in the number of students studying abroad. There are many reasons (educational, political and economic) why the increase of these international exchanges is a good and welcomed phenomenon. It does, however, pose potential challenges for students, instructors and administrators, all of whom must come to understand and reconcile their differing cultural norms (attitudinal and behavioural). Results from the present study indicated that US and Ukrainian students have significantly different sets of norms related to academic dishonesty; the latter viewed cheating behaviour as less wrong than the former and they reported higher levels of engagement in it. The present investigation also suggests that while the adoption of mastery goals was adaptive for students from both countries (i.e., strengthening beliefs about the wrongness of cheating and reducing levels of engagement in it), the relations between academic task value and cheating were moderated by culture (i.e., as Ukrainian students' ratings of their course importance, usefulness and how interesting they found it increased, their beliefs about the wrongness of cheating also increased and their levels of cheating behaviour decreased).

\section{About the authors}

Jason M. Stephens is an Assistant Professor in the Department of Educational Psychology at the University of Connecticut, where he teaches classes on human learning, academic motivation, and research methods. Dr. Stephens' research focuses on the academic motivation and moral development during adolescence. He is particularly interested in the problem of academic dishonesty, and the oft-observed incongruity between students moral beliefs and behaviours related to cheating. $\mathrm{He}$ is a graduate of the University of Vermont (1991), holds an M.Ed degree from Vanderbilt 
University (1994), and a Ph.D. in educational psychology from Stanford University (2004).

Volodymyr Romakin is an Assistant Professor of Computer Sciences at the Petro Mohyla State University, Mykolayiv, Ukraine. He graduated from National University of Shipbuilding, Mykolayiv, Ukraine in 1975. He teachers courses in Electrical Engineering, Automata Theory, Calculation Methods, Statistics, Data Analysis, Informatics and Systemology. His research examines problems of academic integrity in Ukraine and other post-Soviet countries.

Mariya Yukhymenko is a Ph.D. student in Cognition, Instruction, and Learning Technologies at the Department of Educational Psychology at the University of Connecticut. Yukhymenko's research focuses on education within a global context. Specifically, she is interested in motivation and behaviors related to global processes and academic behaviors across cultures. She holds a B.A. and Specialist degree from the T. Shevchenko State Pedagogical University in the city of Chernihiv, Ukraine (2005 and 2006), and a M.A. degree in Educational Psychology, Cognition and Instructions, which she achieved as a Fulbright student, from the University of Connecticut (2009).

\section{References}

Aiken, L. S., \& West, S. G. (1991). Multiple regression: Testing and interpreting interactions. Newbury Park, London: Sage.

Astin, A. W., Parrott, S. A., Korn, W. S., \& Sax, L. J. (1997). The American freshman: Thirty-year trends. Los Angeles: Higher Education Research Institute.

Ames, C. (1992). Classrooms: Goals, structures, and student motivation. Journal of Educational Psychology, 84, 261-271.

Anderman, E. M., Griesinger, T., \& Westerfield, G. (1998). Motivation and cheating during early adolescence. Journal of Educational Psychology, 90(1), 84-93.

Anderman, E., \& Midgley, C. (2004). Changes in self-reported academic cheating across the transition from middle school to high school. Contemporary Educational Psychology, 29, 499-517.

Dee, T. S., \& Jacob, B. A. (2010). Rational ignorance in education: A field experiment in student plagiarism. Working Paper 15672. National Bureau of Economic Research. Retrieved January 23, 2010, from www.nber.org/papers/w15672.

Diekhoff, G. M., LeBeff, E. E., Shinohara, K., \& Yasukawa, H. (1999). College Cheating in Japan and the United States. Research in Higher Education, 40(3), 343-353.

Elliot, A. J. \& McGregor, H. A. (2001). A $2 \times 2$ achievement goal framework. Journal of Personality and Social Psychology, 80(3), 501-519.

Evans, E. D., Craig, D., \& Mietzel, G. (1993). Adolescents' cognitions and attributions for academic cheating: A cross-national study. The Journal of Psychology, 127 (6), 585-602.

Foltz, G., \& Miller, N. (1994). Beliefs and values questionnaire (BVQ) in business ethics: Ethical decision making and cases. Boston: Houghton Mifflin.

Institute of International Education (2008a). International students on US campuses at all-time high. Retrieved February 4, 2009, from http://opendoors.iienetwork.org/? $\mathrm{p}=131590$.

Institute of International Education (2008b). US study abroad up 8\%, continuing decade -long growth. Retrieved February 4, 2009, from http://opendoors. iienetwork.org/? $\mathrm{p}=131592$.

Haines, V.J., Diekhoff, G.M., LaBeff, E.E., \& Clark, R.E. (1986). College cheating: Immaturity, lack of commitment, and the neutralizing attitude. Research in Higher Education, 25, 342-354

Jordan, A. E. (2001). College student cheating: The role of motivation, perceived norms, attitudes, and knowledge of institutional policy. Ethics \& Behaviour, 11(3), 233247. 
Lupton, R. A., \& Chapman, K. J. (2002). Russian and American college students' attitudes, perceptions and tendencies towards cheating. Educational Research, 44(1), 17-27.

Lupton, R. A., Chapman, K. J., \& Weiss, J. E. (2000). A cross-national exploration of business students' attitudes, perceptions, and tendencies toward academic dishonesty. Journal of Education for Business, 75(1), 231-235.

Magnus, J. R., Polterovich, V. M., Danilov, D. L., \& Savvateev, A. V. (2002). Tolerance of cheating: An analysis across countries. Journal of Economic Education, 33, 125-135.

McCabe, D. (1992). The influence of situational ethics on cheating among college students. Sociological Inquiry, 62(3), 365-374.

McCabe, D. (2005). New CAI Research. Retrieved July 29, 2005, from http:// www.academicintegrity.org/cai research.asp

McCabe. D., \& Bowers, W. J. (1994). Academic dishonesty among males in college: A thirty year perspective. Journal of College Student Development, 53, 5-10.

McCabe. D., \& Bowers, W. J. (1996). The relationship between student cheating and college fraternity or sorority membership. NASPA Journal, 33, 280-291.

McCabe, D., \& Trevino, L. K. (1997). Individual and contextual influences on academic dishonesty: A multicampus investigation. Research in Higher Education, 38(3), 379-396.

McCabe, D. L., \& Trevino, L. K. (1993). Academic dishonesty: Honor codes and other contextual influences. Journal of Higher Education, 64(5), 522-538.

McCabe, D. L., Trevino, L. K., \& Butterfield, K. D. (2001). Dishonesty in academic environments: The influence of peer reporting requirements. Journal of Higher Education, 72(1), 29-45.

Murdock, T. B., Hale, N. M., \& Weber, M. J. (2001). Predictors of cheating among early adolescents: Academic and social motivations. Contemporary Educational Psychology, 96(1), 96-115.

Murdock, T. B., Miller, A., \& Kohlhardt, J. (2004). Effects of classroom context variables on high school students' judgments of the acceptability and likelihood of cheating. Journal of Educational Psychology, 96(4), 765-777.

Neutze, J. \& Karatnycky, A. (2007). Corruption, democracy, and investment in Ukraine. Washington, DC: The Atlantic Council of the United States.

Rawwas, M. Y. A., Al-Khatib, J. A., \& Vitell, S. J. (2004). Academic dishonesty: A cross-cultural comparison of US and Chinese marketing students. Journal of Marketing Education, 26, 89-100. Retrieved on November 12, 2008, from http://jimd.sagepub.com.

Rettinger, D. A., Jordan, A. E., \& Peschiera, F. (2004). Evaluating the motivation of students to cheat: A vignette experiment. Research in Higher Education, 45(8), 873-890.

Schraw, G., Olafson, L., Kuch, F., Lehman, T., Lehman, S., \& McCrudden, M. T. (2007). Interest and academic cheating. In E. M. Anderman \& T. B. Murdock (Eds.), Psychology of academic cheating (pp. 59-85). Amsterdam: Academic Press.

Sheehan, K. (2001). E-mail survey response rates: A review. Journal of Computer Mediated Communication, 6(2). Retrieved November 3, 2006, from http:// jcmc.indiana.edu/vol6/issue2/sheehan.html.

Suler, J. (2004). The online disinhibition effect. CyberPsychology and Behaviour, 7 , 321-326.

Transparency International (2009). The Transparency International Corruption Perception Index. Retrieved May 9, 2010, from http://media.transparency.org/ imaps/cpi2009/

Wigfield, A., \& Eccles, J. S. (2000). Expectancy-value theory of achievement motivation. Contemporary Educational Psychology, 25(1), 68-81. 